\title{
Sustainable Tourism Development in Albania through Stakeholders Involvement
}

\section{Rezarta Brokaj}

\author{
PhD Candidate, University “Ismail Qemali” of VIora, Albania, rezartab@gmail.com
}

\section{Merita Murati}

PhD Candidate, "Chamber of Commerce and Industry", Vlore, Albania, meri.murati@gmail.com

\author{
Doi:10.5901/ajis.2014.v3n2p313
}

\begin{abstract}
Tourism is an important subsystem of the Albanian economy, considering a key factor of regional development and economic growth. To ensure the long-term success of the tourism destination on the international tourism market, it has to operate according to the principles of sustainability. The focus of many contemporary studies from the tourism development literature has been on the need of implementing development policies that are based on the principles of sustainable development. The destination can be sustainable and competitive if it attempts to reach a compromise regarding the interests of all the stakeholders. Stakeholder engagement and participatory practice is increasingly becoming a part of mainstream practice and central public policy decision making and delivery related to sustainable tourism. Sustainable development and the application of its principles to Albanian tourism are more important now than ever. It should be examined from the points of view of the key stakeholders: tourists, the local people, the tourism businesses and the professionals involved in the tourism industry. Sustainable tourism development ensures guest satisfaction, steady profit coming from tourism related activities for tourism oriented businesses and growth of tourism in region, rise in standard of living of local people and protection of the environment. Partnership building in Albania is in its infancy and partnership work is essential to get the greatest benefits from the holistic sustainable tourism approach. Hall discussing policy issues regarding tourism states that: often, the problems of developing coordinated approaches towards tourism planning and policy problems, such as the meta problem of sustainability, are identified in organizational terms, e.g the creation of new organizations or the allocation of new responsibilities to existing ones. However, such a response does not by itself solve the problem of bringing various stakeholders and interests together which is an issue of establishing collaborative processes (Hall 1999, 278). The article examines the competitiveness of the Albanian destination from the viewpoints of the tourists, tourism business, local people and tourism experts. Considering each stakeholder's role and protecting the interest of the target groups contributes in achieving and maintaining of sustainability in the tourism sector in Albania. The study aims identifying their attitudes towards sustainability and their points of connection as well that assist with promoting the interests of the target groups. It is critical to note that the participatory engagement of stakeholders is perhaps the most important component of the planning and development of the Albanian destination. It can be described as a process of maturity from initial stages to more developed and self-sustaining stages. Questionnaires were used for gathering data. They were designed for all four target groups. The questionnaires included both open-ended and closed questions.
\end{abstract}

Keywords: Sustainable tourism, stakeholder, destination, Albania

\section{Introduction}

Tourism is considered a valuable economic development opportunity for many countries. The latest annual research from WTTC found that 2013 was another successful year for the Travel \& Tourism sector off the back of an improving economy yet the expansion of tourism worldwide. Travel \& Tourism's contribution equates to $9.5 \%$ of total economy GDP, 1 in 11 of the world's total jobs, $4.4 \%$ of total investment and $5.4 \%$ of world exports. The paper is concerned with sustainable tourism development, the type of tourism widely accepted as the future of tourism sector and the role of stakeholders as the main actors to the ultimate sustainability of tourism development. An initial literature review describes the evolution of theory related to two specific issues in the study of tourism - sustainability of tourism development as a desirable goal and stakeholder participation as a contributor to sustainability. The aim of sustainable tourism is to ensure that development brings a positive experience for local people, tourism companies, and the tourists themselves Simpson (2001: 4).The purpose of this study is to examine the extent to which sustainable development knowledge and stakeholders participation are integrated into the practices of local tourism destinations. The practical value of the 
framework is suggested in an examination of local tourism stakeholders in Vlora region in order to provide a concretization of the theoretical material. While, the integration of sustainable development principles into tourism planning for any type of destination, be it national, regional or local, is vital; a local tourism destination, such as Vlora region is selected by the authors for this investigation due to the fact that it is at the local level where there is considerable opportunity to mitigate the negative impacts of tourism, particularly as local government has the most direct and immediate control over tourism development in the area (Hall, Jenkins and Kearsley, 1997). The case study is an empirical evidence available to argue that the value of these propositions may exist more strongly in theory than in practice.Finally the paper draws some conclusions and recommendations both for sustainable tourism development in Albania and a number of factors which may negatively impact upon the practical implementation of these theoretical constructs in the Albanian context.

\section{Research Methodology}

Research was performed to collect the secondary data regarding relevant literature on the above topics, such as books, previous studies in this field and materials from the internet. The selection of data is done according to the scope of our study. The basis of this study was a survey of community in the Vlora region, focusing on the four main stakeholders categories: local residents, tourists, tourism businesses and local governance. In order to gather information on community' viewpoints in achieving and maintaining of sustainability in the tourism sector in Albania questionnaires were carried out in the region over a six-week period. This study is based upon a qualitative analyses through questionnaires, which included both open-ended and closed questions allowing the researcher some degree of flexibility, in order to insure better and detailed information about sustainable perceptions, attitudes and barriers in the implementation of sustainable tourism development. The survey of tourists visiting the Vlora region were conducted during the summer 2013 (the peak season), the surveys of local residents, entrepreneurs and planners were conducted during September.

A simple random sample total size was set at 208 for the region (the number that agreed to participate, because 32 of the subjects planned refused to answer)

The sample of the business owners included tourism operators, such as hotels, bar and restaurants, travel agencies, recreativeservices suppliers, etc. The sample of local government officials was lower in number, including Tourism Offices representatives (Municipality, Prefecture and District) and professionals organizations in Tourism and Environment. The sampling of tourist and local residents was chosen to reflect not only a geographical distribution, but also a diversification of tourism product, including here sea tourism, cultural tourism, business tourism, special event tourism, etc. Questionnaires were self completed by the most part of subjects included in the study, after informing about the purpose.

The data gathered illustrate that the perception and attitude of sustainable tourism varies considerably among stakeholder groups.

\section{Sustainable Tourism and Stakeholders Role}

Sustainable tourism development guidelines and management practices are applicable to all forms of tourism in all types of destinations, including mass tourism and the various niche tourism segments. Sustainability principles refer to the environmental, economic and socio-cultural aspects of tourism development, and a suitable balance must be established between these three dimensions to guarantee its long-term sustainability.

Thus, sustainable tourism should:

1. Make optimal use of environmental resources that constitute a key element in tourism development, maintaining essential ecological processes and helping to conserve natural resources and biodiversity.

2. Respect the socio-cultural authenticity of host communities, conserve their built and living cultural heritage and traditional values, and contribute to inter-cultural understanding and tolerance.

3. Ensure viable, long-term economic operations, providing socio-economic benefits to all stakeholders that are fairly distributed, including stable employment and income-earning opportunities and social services to host communities, and contributing to poverty alleviation.

Sustainable tourism development requires the informed participation of all relevant stakeholders, as well as strong political leadership to ensure wide participation and consensus building. Achieving sustainable tourism is a continuous process and it requires constant monitoring of impacts, introducing the necessary preventive and/or corrective measures whenever necessary. 
Sustainable tourism should also maintain a high level of tourist satisfaction and ensure a meaningful experience to the tourists, raising their awareness about sustainability issues and promoting sustainable tourism practices amongst them (UNWTO/UNEP, 2005).

This requires the involvement of all stakeholders, as well as ongoing monitoring of the impacts of tourism.

The concept of the sustainable development has become almost universally accepted as a desirable and politically appropriate approach to tourism development (Sharpley, 2003).

Sustainable tourism development meets the needs of the present tourists and host regions while protecting and enhancing opportunities for the future. It is envisaged as leading to management of all resources in such a way that economic, social, and aesthetic needs can be fulfilled while maintaining cultural integrity, essential ecology processes, biological diversity, and life support systems.

According to Farrell and Ward (2005), sustainable tourism is known as a complex industry that co-adapts to the specifics of the particular environment with an important focus on the values and expectations of the local stakeholders, this concept emerged after the Rio Summit in 1992. Berno and Bricker (2001) agree and summarize that the overall aim of the Rio Summit was to bring to light the impacts that tourism can have on a local area, particularly mass tourism. The socio - economic changes in the more developed western countries such as higher incomes, longer holidays, improvements in transportation and cheaper travel costs, provided the means for people to travel in numbers that have never before been realized (Berno et al,2001). Accordingly the approaches outlined in the Brutland Report (1987), aim to protect the environment, improve the social wellbeing of the local community and generate economic benefits.

In an effort to incorporate sustainable concepts into tourism development, many authors have attempted to define or describe sustainable tourism development (Gunn 1994; Hardy \&Beeton 2001; Ioannides 1995; Robson \& Robson 1996; WTO 1998), but there is no universally accepted definition. The definition applied most often by tourism planners and in the tourism research literature was developed by the World Tourism Organization (WTO). The definition is as follows: "Sustainable tourism development meets the needs of the present tourists and host Regions while protecting and enhancing opportunities for the future".

The WTO 's conceptualization of sustainable tourism development addresses six main principles:

- a high level of tourist satisfaction,

- optimal use of environmental resources,

- respecting the socio-cultural authenticity of host communities,

- providing socio-economic benefits to all stakeholders,

- constant monitoring of impacts, and

- informed participation of all relevant stakeholders, as well as strong political leadership.

The principles of sustainability can be applied to any type of tourism - mass or specialty; city, beach, or nature; large or small. They also can be applied to all sectors of the tourist industry: lodging, tours, agencies, ground operators, guiding, and transport. According to Agenda 21 for the Travel \& Tourism Industry, "Sustainable tourism products are products which operate in harmony with local environment, community, and cultures, so that these become the permanent beneficiaries."The support of tourism stakeholders is essential for the development, successful operation, and long-term sustainability of tourism. Tourism stakeholders include many different types of groups depending on geographically - based in the different parts of the area.A stakeholder is, "any group or individual who can affect or is affected by the achievement of the organization's objectives" (Freeman,1984). Translating Stakeholder Theory to tourism "Freeman's concepts requires the tourism planner(s) to have a full appreciation of all the persons or groups who have interests in the planning, process(es), delivery and/or outcomes of the tourism service" (Sautter and Leisen).

The relative weight and importance of the subjects related to sustainable development is hardly objectively determinable and depends on the values and ideologies of various stakeholders (Hall, 1998).

Numerous studies have examined the involvement of community participation in the tourism development process (Tosun, 2000; Tosun, 2006; Li, 2005; Li, 2004; Timothy, 1999). The process of tourism development as pointed out in the works of Doxey (1976); Butler (1976,1980); Keller (1984) as cited in Simmons (1994) and Tosun (2000), appears to suggest that there is a high degree of dependence on residents for their acceptance of the industry before it starts in a particular destination.

"Without community support, it is difficult to develop a sustainable tourism industry in a community." - Andereck and Vogt, 2000. New research is focusing on resident's attitudes towards sustainable tourism development (Choi and Sirakaya, 2005 and 2006 ). As the tourist industry becomes increasingly important to communities around the world, the need to develop tourism sustainably has also become a primary concern.

As a widely accepted criterion of sustainable tourism (e.g. Pigram 1994), 'community participation' has been widely 
promoted and debated for several reasons:

- local involvement in development processes is likely to assist the formulation of more appropriate decisions and to generate an increase in local motivation;

- support for environmental conservation and protection measures is likely to be greater (Tourism Concern 1992);

- as a service industry, tourism requires the goodwill and co-operation of host communities (Simmons 1994);

- visitor satisfaction is likely to be greater where 'hosts' support and take pride in their tourism (Cole 1996).

\section{A Brief View of Tourism Development in Albania}

Albania represents a country which has considerable potential to be used for tourism development, by presenting the image of a relatively new tourist destination. Albania has so much to offer to tourists in terms of its hugely diverse natural beauty, its culture, its heritage and archeological sites. It also benefits from a wonderful Mediterranean climate. Albania offers infinite potential to investors to take advantage of unexplored opportunities in tourism, and helping to develop this industry into a key strategic sector in the country's economy.During this period of time, the number of tourists has continuously increased by maintaining a constant number of ethnic tourists.

According to the World Travel and Tourism Council, the economic contribution of Travel and Tourism in Albania are presented in the table below.

Table 1. Tourism estimates and forecast for Albania

\begin{tabular}{|l|c|c|c|c|c|c|}
\hline \multirow{2}{*}{ Albania } & 2013 & 2013 & 2014 & \multicolumn{3}{|c|}{2024} \\
ALL bn & $\%$ of total & Growth & \multicolumn{2}{|c|}{ ALL bn\% of total } & Growth \\
\hline Direct contribution to GDP & 68.1 & 4.8 & 5.5 & 123.6 & 6.1 & 5.6 \\
Total contribution to GDP & 239.8 & 16.7 & 4.6 & 424 & 20.9 & 5.4 \\
Direct contribution to employment & 4.1 & 4.3 & 5.2 & 61 & 5.7 & 3.5 \\
Total contribution to employment & 147 & 15.2 & 4.1 & 210 & 19.5 & 3.2 \\
Visitor exports & 154 & 23.2 & 6.3 & 282.5 & 22.2 & 5.6 \\
Domestic spending & 32 & 2.2 & 2.3 & 53.4 & 2.6 & 5 \\
Leisure spending & 143.7 & 3.7 & 5.2 & 268.8 & 4.9 & 5.9 \\
Business spending & 42.2 & 1.1 & 6.9 & 67.1 & 1.2 & 4 \\
Capital investment & 15.4 & 4.3 & -2.2 & 22.5 & 4.4 & 4.1 \\
\hline
\end{tabular}

Source: World Travel and Tourism Council

However, the fact that the sector relies heavily on destinations' natural, cultural and heritage attractions for survival, may also result in the overuse of these very resources, and may threaten their successful maintenance, and even existence in the long-term. As a means of reducing the negative effects of mass tourism development and as a more appropriate model for the scale and nature of Albania, the solution is sought in sustainable tourism development. Sustainable tourism development aims to reduce the adverse impacts and costs of the tourism sector, while optimizing its benefits shared by the sector's stakeholders ranging from host communities to visitors. The foremost challenge of the process, therefore, rests in the identification of the activities and facilities triggering such adverse effects in the natural, socio-cultural and economic environments of a tourist destination, while ensuring the longevity of irreplaceable tourist resources that would help the Albanian destination to retain its competitive advantage in the long- term.

The Strategy for Tourism Development in Albania was approved in 2007 -2013 and it was designed to expand and strengthen this sector, focusing particularly on the sustainable development principle and on the identification of challenges to optimize contributions to this sector. But many barriers were identified in the efforts for the implementation of this strategy. Though seven years have passed, there are still important aspects of the strategy and its plans of action which have not been achieved. The two main problems are related to:

- the sustainable development of the product and the application of the sustainability principle at all levels;

- the creation of institutional structures, both at central and local level, which would guarantee the implementation of plans and strategic objectives

Vlora region is the area of study. It is the main tourist destination in Albania. Region of Vlora is situated in the southwestern part of Albania and represents extraordinary interest in national and international plan. A Very favorable 
geographical position, the rich history, the excellent traditions, the present developments, quantitative and qualitative dimensions, instates Vlora in new dimensions towards a sustainable development.

The development of a stable and sustainable economy base is an absolute priority for this region. In March 2010, the Region launched a strategic planning process within the framework UNDP ART GOLD 2 Program. This Strategic Plan is a territorial growth and renewal platform aimed to attain an endogenous and sustainable development model through the involvement of the entire cultural, environment, social and economic components of a particular area. The Strategic Plan is an innovative an flexible territorial governance instrument, already applied in several European cities, intended to provide a clear direction on local development policy.

\section{Results and Discussion}

Questionnaires used for gathering data were designed for all four target groups of stakeholders: local residents, tourists, tourism businesses and local governance. The questionnaires included 26 questions; the majority were open-ended questions and the rest were closed questions, with multiple choice. All in all, 208 people out of 240 have responded to the questionnaire, which is a response rate of $87 \%$.

The questionnaire was structured in four parts, as follow:

The first section (consisting of 10 question; 4 of them focused on the general description of stakeholders) deals with the extent to which the concept of the sustainable tourism is recognized by the community. The four target groups of the community were asked whether they are familiar with the concept of sustainable development and how do they describe it.

The second section (consisting of 4 questions) deals with the importance of the sustainable tourism development from the viewpoint of stakeholders.

The third section (consisting of 7 questions) is related with the implementation of sustainable tourism and the behavior of the target groups regarding that.

The forth section (consisting of 5 questions) deals with the leading process of sustainable tourism.

Questions were directed towards finding out answers to these issues. Without a clear understanding of the issues by stakeholders it is difficult or impossible for them to make sound decisions in regards to the tourism development and management in their communities.

This paper identifies the key tourism stakeholder's knowledge of sustainable tourism and in implementing its development and provide a synthesis of the similarity and differences in the characteristics of the tourism stakeholders found in Vlora region.

The overall attitude of stakeholders toward tourism is positive. They see tourism as the main branch for the development of local economy. The results show that support for the tourism industry is strong among the local residents, tourism businesses and governance bodies. Furthermore, they not only support the current size of the industry, but are also in favor of its expansion, excepting the tourists, whose decision for choosing Vlora as tourist destination is largely affected by the current phase of the destination life cycle. Local community also perceived negative changes as consequences of the impacts of the tourism industry in the region. The most strongly perceived negative impact is related to the environmental aspects and the reduction of public spaces and coastline usable by residents.

\subsection{The concept of sustainable development}

$68 \%$ of the respondents are familiar with the concept of sustainable development. People with a higher education are significantly more familiar with sustainable development than lower and medium educated people. The respondents were asked to identify a description that best fits their idea of sustainable development. There is an almost equal distribution between those who chose the environment related option (49\%) and those who identified the description of sustainable development as a balanced development of economy, environment and society (51\%). However, when confronted with a number of concrete topics that are all part of sustainable development, $87 \%$ of the respondents thought of environmental issues. Social issues were next, with $71 \%$, issues related to the long-term came on the third place with $62 \%$, followed by institutional issues with $56 \%$, economy related issues came on the fifth place with $48 \%$ and information technology came last with $39 \%$. Only the governance bodies understand it as a balanced development of society, economy and the environment both as a concept and as a model to be applied in practice.

From this we can conclude that sustainable development is relatively well-known, but no understood in the right way. 


\subsection{The importance of sustainable tourism}

$63 \%$ of the respondents think sustainable development is important, $16 \%$ thinks sustainable development in not important but not unimportant either and $17 \%$ think it is very important. Only $4 \%$ of the respondents say sustainable development is not important. The respondents who are familiar with sustainable development more often say sustainable development is important or very important than those who are unfamiliar. Those who are unfamiliar with sustainable development more often say it is neither important nor unimportant. Lower educated respondents more often are neutral than the higher educated respondents.

\subsection{Implementation and attitude towards sustainable tourism}

Because sustainable development is such a complex and abstract concept, it is assumed that people might not recognize what they do as being sustainable. Therefore, a large part of the questionnaire was devoted to finding out which actions people carry out and whether the considerations that are at the basis of their decisions are related to sustainable development. Although the majority of the respondents think sustainable development of tourism is important, when asked about concrete actions in implementing the sustainable development, they mainly choose environmental issues. The results for the other two pillars of sustainability are less homogeneous than for environmental behavior.

The stakeholders were asked if they wanted to become more sustainable in the future. The majority of respondents say they want to live more sustainable (94\%), but the answers were divided in two categories: local planners and business owners included in the first category claim to agree with the principles of sustainable tourism and they would like to implement it, but if it does not take more money. The tourist operators efforts in providing sustainable products are relatedly low. Their budget in implementing the sustainable tourism actions is very limited. At the other side, the tourists and the residents pretend they are willing to behave more sustainable, if this will be the future trend. This is related with the individual benefits they think sustainable tourism will provide for them. However, the study of people's behavior gives us some indications of the barriers that need to be bridged for people to become more sustainable.

So, it is necessary to entail information that provides concrete examples of what sustainable development can mean. If the main actors do not know what sustainable development entails, they will probably not call their behavior and actions sustainable.

From this we can conclude that although environmental consciousness has become mainstream, sustainability consciousness is not yet a common thing. Responders mention that they have received information on sustainable development only to a limited extent. This might be one reason why they do not act sustainably. So, information on sustainable development in general is needed because once players are familiar with the concept, they are more accepting of higher costs in time and money.

\subsection{Leading and coordinating role}

Almost all the stakeholders agree that the leading role belongs to the local planners (93\%). In general, residents in Vlora city believe in leading role of local governance - municipalities and the provincial administration more than higher level government entities. According to the respondents, government should ensure sustainable tourism by providing information for products and services, legislation and regulation, coordinating the activities of all groups and monitoring all the activities. But they have no clear idea what exactly expect government to take action.

Of special interest is the fact that respondents say that at all levels (national, regional and local), setting vision and goals for the future is very important. Marketing activities for Vlora as a tourist destination are a weak point in sustainable development strategies and thus is definitely an area of concern.

To make the results of the study applicable to the whole Albanian destination, it would be necessary to carry out a more exhaustive and comprehensive investigation and analysis over a longer period.

\section{Conclusion and Recommendations}

Sustainable tourism development is considered an appropriate development concept for the Albanian destination. In order for sustainable tourism development to be implemented successfully, there is a need to identify the key stakeholders knowledge and attitude towards that process. All the stakeholder groups think sustainable development is important. However, they understand sustainable development at a conceptual level, but interpret it mainly as environment at a concrete level. An interesting result of the study is that not all stakeholders have the same level of interest in sustainable tourism development and may be less active or not active at all. 
An issue that should be pointed out is that there is a large difference between the attitudes of the four players, which is a barrier to implementation. If policy on sustainable development is not properly communicated in such a way that people can understand what is meant, it will be very difficult to implement. This gap in implementation can be filled by the coordination role of the local governance for involvement and participation of all stakeholders, development of the sustainable tourism strategy, setting objectives and vision.

Taking into account the findings from the analysis of questionnaire data, authors of the paper make some recommendations for further understanding and implementation of sustainable tourism in Vlora region:

- policies toward sustainable tourism development require the integration of environmental, social and economic objectives into a coherent strategy;

- information is needed about the interrelatedness of the three pillars of sustainability and individual benefits effects of sustainable behavior for all the stakeholders;

- certification programs for tourism businesses setting standards for sustainability;

- prerequisite to a sustainable planning approach should be stakeholder participation;

- development of a tourist product with long-term production features;

- continuous protection, implementation and respect of high ecological standards and long-term sustainable assessment of tourist potentials;

- education of all management and other staff levels in sustainable tourism principles;

- development of an integrated offer in a tourist destination;

- economic incentives and environmental education on local capacity building;

- public-private partnership and

- emergence and implementation of a participatory tourism development.

\section{References}

Freeman, R.E. (1984). Strategic management: A stakeholder approach. Boston: Pitman Hall, C M, (2000), Tourism Planning: Policies, Processes and Relationships, Prentice Hall. Richard Sharpley Tourism, Tourists and Society Elm Publications, (2003) - Economic development Greg Richards, Derek Hall, (2002) Tourism and sustainable community development. Butler, R., Hall, C. and Jenkins, J. (1998). Introduction, in Butler, R., Hall, C. and Jenkins, J. (eds) Bryan Farrell, Louise Twining-Ward, (2005).Seven Steps Towards Sustainability: Tourism in the Context of New Knowledge Tracy Berno , Kelly Bricker , (2001) Sustainable tourism development: the long road from theory to practice Gunn, C.A. (1994). Tourism planning: Basic concepts cases (3rd ed.). Washington, D.C.: Taylor and Francis Meuleman, Louis and Roel J. in 't Veld (2009): Sustainable Development and the Governance of Long-Term Decision Making. The Hague: RMNO/EEAC.

Annemarie van Zeijl-Rozema, Ron Cörvers, René Kemp Governance for Sustainable Development: A Framework and Pim Martens1. Glasbergen, P., P.P.J. Driessen, 'The Paradigm Shift in Environmental Politics', In: P.P.J. Driessen and P. Glasbergen, Greening Society. The paradigm shift in Dutch environmental politics, Kluwer Academic Publishers, 2002, chapter 1.

Simpson, Ken (2001) Strategic Planning and Community Involvement as Contributors to Sustainable Tourism Development, Current Issues in Tourism

Jennings, Gail (2001) Tourism Research. Milton, Queensland: John Wiley and Sons

Hall, C.M., Jenkins, J. and Kearsley, G.W.A. Introduction: issues in tourism planning and policy in Australia and New Zealand. In Tourism Planning and Policy in Australia and New Zealand: Cases, Issues and Practice. C.M. Hall

Hardy, A. L. and Beeton, R. J. S. (2001) Sustainable Tourism or Maintainable Tourism: Managing resources for more than average outcomes, Journal of Sustainable Tourism, 9, 3, 168-192

Jan Kooiman, Governing as Governance SAGE Publications, (2003) - Political Science - 249

Kemp, R. and P. Martens (2007). "Sustainable Development: how to manage something that is subjective and that never can be reached?" Sustainability: Science, Practice \& Policy, e-journal

René Kemp* and SaeedParto, Governance for sustainable development: moving from theory to practice

Sautter, E. T. and Leisen, B. (1999). Managing stakeholders: A tourism planning model. Annals of Tourism Research, 26(2), 312 - 328

Van den Hove, S. (2000). Participatory Approaches to Environmental Policy-Making: the European Commission Climate Policy Process as a case study, Ecological Economics, 33; 457-472

Policy and Practice for Global Tourism - WTO 2011 - www.unwto.org

Republic of Albania, Ministry of Tourism, Culture, Youth and Sports - Sector Strategy on Tourism 2007 - 2013

World Travel and Tourism Council "Economic impact 2014 Albania" http://www.wttc.org/site_media/uploads/downloads/albania2014.pdf

WTTC, WTO, Earth Council, Agenda 21 for the Travel \& Tourism Industry, 1996, www.wttc.org/agenda21.htm

UNWTO, Handbook, 2011, p. 11

UNWTO, Communicating Heritage: A Handbook for the Tourism Sector, 2011, p. 19 
